\title{
Acute quadriparesis in an asthmatic treated with atracurium
}

Claude P. Tousignant MD FRCPC, ${ }^{*} \dagger$

David R. Bevan MB FRCA MRCP, ${ }^{*}$

Andrew A. Eisen MD FRCP, $\rfloor$ John C. Fenwick MD FRCP, $\dagger$ Martin G. Tweedale MB FRCP ${ }^{\dagger}$
An 18-yr-old male asthmatic was paralyzed with atracurium for a period of seven days to facilitate mechanical pulmonary ventilation. After withdrawal of the muscle relaxant, train-offour neuromuscular monitoring demonstrated rapid recovery of normal function. Three days later he developed acute quadriparesis without respiratory compromise. Electrophysiological studies showed normal conduction velocities, low compound muscle action potential amplitudes and evidence of denervation. Most cases of post-ventilatory weakness in the ICU involve the use of vecuronium and pancuronium. It has been suggested that the steroid nucleus in these muscle relaxants may be responsible. Our patient developed generalised weakness after treatment with atracurium, a benzylisoquinolinium muscle relaxant. Thus, it appears that the steroid nucleus of vecuronium and pancuronium is not essential in causing post-ventilatory weakness.

Un asthmatique de 18 ans est curarisé à l'atracurium pendant sept jours pour la ventilation mécanique. Après l'arrêt du myorelaxant, la fonction neuromusculaire telle qu'évaluée au trainde-quatre récupère rapidement. Trois jours plus tard, le patient devient subitement quadriplégique sans atteinte respiratoire. $A$ l'électrophysiologie, les vélocités de conduction sont normales, les composantes des potentiels d'action sont de faible amplitude et la dénervation est évidente. A l'unité de soins intensifs, la majorité des cas de faiblesse ventilatoire survient avec le vécuronium et le pancuronium. La cause du problème est ordinairement attribuée au noyau stéroïde de ces relaxants. Dans le cas présent, la faiblesse généralisée est survenue après un traitement à l'atracurium qui est dérivé du benzylisoquinoli-

\section{Key words}

COMPLICATIONS: weakness, asthma; MUSCLE RELAXANTS: atracurium.

From the Departments of Anaesthesia*, Critical Care $\dagger$ and Neurology $\ddagger$ University of British Columbia, Vancouver General Hospital, Vancouver, British Columbia.

Address correspondence to: Dr. Claude Tousignant,

Department of Anaesthesia, St. Michael's Hospital, 30 Bond

Street, Toronto, Ontario, MSB 1W8.

Accepted for publication 20th November, 1994. nium. Il ne semble donc pas que le noyau stéroïde du vécuronium et du pancuronium puisse être considéré comme le facteur essentiel de la faiblesse post-ventilatoire.

There is an increasing number of case reports describing acute weakness in healthy asthmatics who require mechanical ventilation and are treated with steroids and muscle relaxants. ${ }^{1-12}$ These patients exhibit moderate to severe quadriparesis with or without areflexia but they usually retain normal sensory function. The pathophysiology of this weakness is not well understood but muscle relaxants have been implicated, in particular the aminosteroids pancuronium and vecuronium. It has been suggested that the steroid nucleus in pancuronium and vecuronium might be involved in the development of weakness. ${ }^{4,5,12,13}$ We describe a case of acute quadriparesis in a young asthmatic after receiving an infusion of atracurium, a benzylisoquinolinium muscle relaxant unrelated structurally to pancuronium or vecuronium, to facilitate mechanical ventilation. The infusion was continued for seven days and neuromuscular monitoring demonstrated rapid and complete recovery of neuromuscular function three days before the development of generalised weakness.

\section{Case report}

An 18-yr-old $66 \mathrm{~kg}$, Japanese man was admitted to the intensive care unit in status asthmaticus. Immediate intervention consisted of tracheal intubation and mechanical ventilation followed by a course of isoflurane inhalational therapy. Additional medications included methylprednisolone $125 \mathrm{mg} \dot{\sim}$ every six hours for five days followed by $75 \mathrm{mg} i v$ every six hours. Intravenous aminophylline and salbutamol were also administered. Antibiotics included ceftizoxime and erythromycin. Sedation was accomplished with midazolam and fentanyl. To facilitate mechanical ventilation the patient was paralyzed with atracurium for $164 \mathrm{hr}$ (seven days) for a total dose of $7230 \mathrm{mg}$. Neuromuscular function was monitored every four hours using a peripheral nerve stimulator (Dual Stim Plus, Life Tech Inc, Houston TX) which provided train-of-four stimulation of the ulnar nerve. The dose of atracurium was adjusted so that only the response 
at the adductor pollicis to the first stimulus of the trainof-four was visible. Hourly atracurium requirements ranged from 10 to $15 \mu \mathrm{g} \cdot \mathrm{kg}^{-1} \cdot \mathrm{min}^{-1}$ with no increase over the course of seven days. Once ventilatory status had improved, muscle relaxation was discontinued and recovery from neuromuscular blockade was measured with a Grass S88 (Grass Instruments, Quincy, Mass.) peripheral nerve stimulator. Surface electrodes were applied over the ulnar nerve at the wrist and the force of contraction of the adductor pollicis muscle was measured with a Grass FT-10 force transducer. Supramaximal stimulation of $0.2 \mathrm{msec}$ duration at a frequency of $2 \mathrm{~Hz}$ was applied to the ulnar nerve every $12 \mathrm{sec}$. Control measurements were taken as the height of the first twitch $\left(\mathrm{T}_{1}\right)$ of the train, once the train-of-four ratio reached 0.8 . The $25 \%-75 \% \mathrm{~T}_{1}$ recovery index was $22 \mathrm{~min}$. There was no metabolic disturbance upon discontinuation of atracurium. Serum creatine phosphokinase increased from 112 $\mathrm{U} \cdot \mathrm{L}^{-1}$ on admission to $763 \mathrm{U} \cdot \mathrm{L}^{-1}$ seven days later on discontinuation of atracurium. Initially, the patient did not appear weak and had normal deep tendon reflexes. He remained sedated with midazolam and fentanyl. Methyltrimeprazine was added for restlessness. On the eighth day he opened his eyes and moved all limbs to command. On the ninth day he was more restless and was noted to be actively moving around in bed. He was able to sit up and dangle his legs over the side of the bed with assistance. On the tenth day the trachea was extubated and again he could sit up and dangle his legs with some assistance. However, later that day on the ward he was noted to have difficulty holding his head up. The next morning, he was noted to be profoundly weak. He was quadriplegic save for some finger and hand movement as well as some foot movement. He did not appear to have any sensory or bulbar deficits.

Electrophysiological studies were performed at 15 and 21 days after admission. The first examination revealed normal motor and sensory nerve conduction velocities with small compound muscle action potentials in the arms and legs. There was no evidence of a transmission defect either to slow or fast stimulation rates. Needle electromyography (EMG) studies showed early evidence of denervation with membrane irritability and occasional fibrillations, particularly in the tibialis anterior. The second electrophysiological examination was similar to the first with moderate denervation, fibrillation and positive sharp waves in both anterior and posterior compartments of the legs in a fairly symmetrical fashion. By the 18th day after admission, he had regained considerable arm function with good strength but lower limbs remained weak. He did not exhibit any deep tendon reflexes. He returned to Japan before a muscle biopsy could be performed.

\section{Discussion}

Our patient, a known asthmatic, developed diffuse muscle weakness with normal sensory function after a period of mechanical ventilation facilitated by muscle paralysis with atracurium. Train-of-four monitoring demonstrated full return of neuromuscular function. Although the patient did not regain full strength upon discontinuation of the muscle relaxant, he was able to mobilize and the trachea was extubated soon thereafter. Profound weakness did not occur until three days later. Electrophysiological studies at 15 days after admission demonstrated normal conduction in the face of low compound muscle action potential amplitude. Further studies, at 21 days, revealed evidence of denervation and again a neuromuscular transmission defect could not be demonstrated. These findings are consistent with a very distal lesion of the motor unit. No metabolic disturbances could be found to account for such a weakness. There was no respiratory compromise.

There are many reports of generalised weakness developing in critically ill patients. Several possible causes have been suggested. These include prolonged neuromuscular block and steroid myopathy. In this patient, prolonged neuromuscular block is unlikely since testing of neuromuscular function demonstrated normal recovery after stopping the infusion. Furthermore, electrophysiological studies did not demonstrate any evidence of a transmission defect. A pure steroid myopathy is also unlikely because it takes a long time to develop and affects more proximal muscles preferentially.

Critical Illness polyneuropathy as described by Zochodne et al. ${ }^{13}$ a combined sensory and motor neuropathy occurring in $50 \%$ of patients who have been septic for longer than two weeks, ${ }^{14,15}$ is a potential cause of weakness in critically ill patients. The muscle itself may also be involved. ${ }^{15}$ Patients may demonstrate a reduction in compound muscle action potential amplitude as well as fibrillation potentials and signs of denervation. Sensory compound action potentials may be decreased or absent. Electrophysiological examinations are consistent with primary axonal degeneration of peripheral nerve fibres. ${ }^{15}$ There is no evidence that muscle relaxants alone cause a polyneuropathy or a myopathy. Polyneuropathy due to sepsis plus muscle relaxants and polyneuropathy due to sepsis, muscle relaxants and steroids, as proposed by Bolton ${ }^{15}$ may not exactly fit the clinical picture in our patient who was not septic while in the intensive care unit, and he did not demonstrate signs of polyneuropathy.

Danon et al. ${ }^{\prime}$ described an asthmatic treated with vecuronium and steroids who developed flaccid quadriplegia. The patient had normal sensory and motor nerve conduction velocities and increased creatine phosphokinase. The EMG showed diffuse fibrillation potentials and 
low amplitude motor action potentials. Muscle biopsy showed extensive atrophy with loss of thick myofilaments with preservation of thin myofilaments. They suggested that the pathological lesions resembled those seen in animals ${ }^{16}$ following denervation and treatment with steroids. Rouleaux et al. ${ }^{16}$ demonstrated diffuse atrophy greater than when denervation or steroids were administered alone. There was considerable loss of thick filaments and myosin depletion. Several authors have suggested that administration of muscle relaxants in therapeutic doses in the intensive care unit may lead to pharmacological denervation, ${ }^{5,10,18}$ which may be analogous to the denervation in the animal models described above. In an effort to avoid prolonged block, neuromuscular complications and complete interruption of neuromuscular transmission, strict titration of atracurium to one twitch of the trainof-four was maintained. This did not prevent the development of weakness.

Most reports of weakness in asthmatics involve the use of vecuronium or pancuronium. It has been suggested that the steroidal nature of these muscle relaxants might have some role in its development. ${ }^{4,5,12,13}$ The fact that our patient developed weakness after recovery from atracurium, a benzylisoquinolinium, suggests that the molecular structure of the muscle relaxant is not a relevant factor, and that weakness may occur with non-steroidal neuromuscular blocking drugs.

Meyer $e t$ al. ${ }^{19}$ have recently reported two cases of muscle weakness evident soon after the withdrawal of prolonged infusions of atracurium. Both patients were treated with systemic steroids and lend further support to the hypothesis that weakness may occur with the administration of a benzylisoquinolinium muscle relaxant. The EMG findings were similar to ours with small amplitude motor unit potentials with early evidence of reinnervation. One patient did demonstrate nerve conduction abnormalities. The major difference between our patient and those of Meyer, ${ }^{19}$ is that we did not observe immediate weakness and we were able to wean the patient from mechanical ventilation and extubate the trachea. Profound weakness followed one day later. We were also able to demonstrate rapid and complete resolution of neuromuscular blockade at the time of discontinuation. It is clear from these case reports that the time course and extent of weakness can be variable and that weakness may progress to an extensive degree despite the discontinuation of the muscle relaxants.

Several causes have been proposed to account for postventilatory weakness. They include prolonged neuromuscular blockade resulting from organ dysfunction or active metabolites as well as metabolic disorders and polypharmacy. Finally, steroid myopathy, polyneuropathy of sepsis, polyneuropathy of sepsis with muscle relaxants or polyneuropathy of sepsis with muscle relaxants and steroids are other entities which may be responsible for weakness. Our patient did not exhibit signs of polyneuropathy. It has been demonstrated in animal studies that the number of steroid receptors in muscle increases following denervation. ${ }^{17}$ In this situation, the muscle may be more vulnerable to the myopathic effects of systemically administered steroids. Although our patient's weakness may have been the result of a myopathy, a pure disorder of the muscle fibre per se was not confirmed. Alternatively, weakness may not be the result of a polyneuropathy but that of a neuromuscular junction disorder, diffuse or patchy, with or without a myopathic involvement. The role of muscle relaxants in the development of weakness is uncertain but pharmacological denervation $5,10,18$ analogous to denervation in animal models ${ }^{16}$ is possible. The administration of glucocorticoids prior to therapy with muscle relaxants may increase the risk of developing weakness. Reinnervation associated with the removal of muscle relaxants usually results in a restoration of strength; however, weakness, as in our case, may continue to progress. Further clinical EMG studies of critically ill patients treated with muscle relaxants may help elucidate this problem. The steroidal nucleus of pancuronium and vecuronium does not appear to be essential.

\section{References}

1 Danon MJ, Carpenter $S$. Myopathy with thick filament (myosin) loss following prolonged paralysis with vecuronium during steroid treatment. Muscle Nerve 1991; 14: 1131-9.

2 Williams TJ, O'Hehir RE, Czarny D, Horne M, Bowes G. Acute myopathy in severe acute asthma treated with intravenously administered corticosteroids. Am Rev Respir Dis 1988; 137: 460-3.

3 Gorson $K C$, Ropper $A H$. Acute respiratory failure neuropathy: a variant of critical illness polyneuropathy. Crit Care Med 1993; 21: 267-71.

4 Kupfer Y, Namba T, Kaldawi E, Tessler S. Prolonged weakness after long-term infusion of vecuronium bromide. Ann Intern Med 1992; 117: 484-6.

5 Griffin D, Fairman N, Coursin D, Rawsthorne L, Grossman $J E$. Acute myopathy during treatment of status asthmaticus with corticosteroids and steroidal muscle relaxants. Chest 1992; 102: 510-4.

6 Kupfer Y, Okrent DG, Twersky RA, Tessler S. Disuse atrophy in a ventilated patient with status asthmaticus receiving neuromuscular blockade. Crit Care Med 1987; 15: 795-6.

7 MacFarlane IA, Rosenthal FD. Severe myopathy after status asthmaticus (Letter). Lancet 1977; 2: 615.

8 Sitwell LD, Weinshenker BG, Montpetit V, Reid D 
Complete ophthalmoplegia as a complication of acute corticosteroid- and pancuronium-associated myopathy. Neurology 1991; 41: 921-2.

9 Apte-Kakade S. Rehabilitation of patients with quadriparesis after treatment of status asthmaticus with neuromuscular blocking agents and high-dose corticosteroids. Arch Phys Med Rehabil 1991; 72: 1024-8.

10 Gooch $J L$, Suchyta MR, Balbierz JM, Petajan JH, Clemmer TP. Prolonged paralysis after treatment with neuromuscular junction blocking agents. Crit Care Med 1991; 19: 1125-31.

11 Douglas JA, Tuxen DV, Horne $M$, et al. Myopathy in severe asthma. Am Rev Respir Dis 1992; 146: 517-9.

12 Pollard $B$. Which drug - steroid or benzylisoquinolinium? Intensive Care Med 1993; 19: S86-90.

13 Kaplan PW, Rocha W, Sanders DB, D'Souza B, Spock $A$. Acute steroid-induced tetraplegia following status asthmaticus. Pediatrics 1986; 78: 121-3.

14 Zochodne DW, Bolton CF, Well G, et al. Critical illness polyneuropathy: a complication of sepsis and multiple organ failure. Brain 1987; 110: 819-42.

15 Bolton CF. Neuromuscular complications of sepsis. Intensive Care Med 1993; 19: S58-63.

16 Rouleaux G, Karpati G, Carpenter S, Soza M, Prescott S, Holland $P$. Glucocorticoid excess induces preferential depletion of myosin in denervated skeletal muscle fibres. Muscle Nerve 1987; 10: 428-38.

17 DuBois DC, Almon RR. A possible role for glucocorticoids in denervation atrophy. Muscle Nerve 1981; 4: 370-3.

18 Chad $D A$, Lacomis $D$. Critically ill patients with newly acquired weakness: the clinicopathological spectrum. Ann Neurol 1994; 35: 257-9.

19 Meyer KC, Prielipp RC, Grossman JE, Coursin DB. Prolonged weakness after infusion of atracurium in two intensive care unit patients. Anesth Analg 1994; 78: 772-4. 